\title{
(n)
}

\section{Scoping review of factors influencing the implementation of group psychoeducational initiatives for people experiencing mental health difficulties and their families}

\section{Agnes Higgins, Rebecca Murphy, Jennifer Barry, Jessica Eustace-Cook, Mark} Monahan, Thilo Kroll, David Hevey, Louise Doyle \& Patrick Gibbons

To cite this article: Agnes Higgins, Rebecca Murphy, Jennifer Barry, Jessica Eustace-Cook, Mark Monahan, Thilo Kroll, David Hevey, Louise Doyle \& Patrick Gibbons (2020): Scoping review of factors influencing the implementation of group psychoeducational initiatives for people experiencing mental health difficulties and their families, Journal of Mental Health, DOI: 10.1080/09638237.2020.1714002

To link to this article: https://doi.org/10.1080/09638237.2020.1714002

\section{曲 Published online: 29 Jan 2020.}

Submit your article to this journal

Џll Article views: 454

Q View related articles $₫$

View Crossmark data \lceil 


\title{
Scoping review of factors influencing the implementation of group psychoeducational initiatives for people experiencing mental health difficulties and their families
}

\author{
Agnes Higgins ${ }^{a}$, Rebecca Murphy ${ }^{a}$, Jennifer Barry ${ }^{a}$, Jessica Eustace-Cook ${ }^{b}$, Mark Monahan ${ }^{a}$, Thilo Kroll ${ }^{c}$ (D), \\ David Hevey $^{d}$ (D) Louise Doyle ${ }^{a}$ (D) and Patrick Gibbons ${ }^{e}$ \\ ${ }^{a}$ School of Nursing and Midwifery, Trinity College Dublin, Dublin, Ireland; ${ }^{\text {Library, Trinity College Dublin, Dublin, Ireland; ' } \mathrm{C} S c h o o l}$ of \\ Nursing, Midwifery and Health Systems, University College Dublin, Dublin, Ireland; ' ${ }^{\mathrm{d}}$ School of Psychology, Trinity College Dublin, Dublin, \\ Ireland; ' Kildare West Wicklow Mental Health Service, Naas Hospital, Naas, Ireland
}

\begin{abstract}
Background: Despite evidence to support the effectiveness of psychoeducation for people experiencing mental health difficulties and their families, understanding issues around the implementation of such programmes is limited.

Aim: The aim of this scoping review was to synthesise the peer-reviewed literature on barriers and enablers influencing the implementation of group psychoeducation in adult mental health services.

Methods: Using a pre-defined search strategy and PRISMA guidelines, four databases were systematically searched. Two reviewers independently screened and applied exclusion/inclusion criteria. Qualitative, quantitative, and mixed-methods studies were included if they provided empirical evidence on the barriers and enablers. Three reviewers independently extracted data. Following this, data were analysed using a five-level implementation framework.

Results: Eight articles met the inclusion criteria. Barriers to implementation were identified at all five levels of the framework: participant; practitioner; intervention; organisational; and structural level. Enablers to implementation were evident at four levels: participant; provider; intervention; and organisational level.

Conclusions: The findings of the review provide preliminary information on factors that impact implementation. However, large-scale studies informed by implementation theories are required. In addition, other studies are needed to address the potential impact of different models of intervention and explore strategies to minimize obstacles and support sustainability.
\end{abstract}

\section{ARTICLE HISTORY}

Received 1 May 2019

Revised 16 September 2019

Accepted 26 November 2019 Published online 23 January 2020

\section{KEYWORDS}

Psychoeducation; Group intervention; barriers; enablers; mental health; service users; patients; family; adult mental health services; scoping review

\section{Introduction}

Internationally, a policy mandated shift is occurring in mental health services towards the adoption of recovery-oriented care (WHO, 2013). The concept of recovery refers to a philosophy and approach that promotes an individual's personal resourcefulness, autonomy, positive sense of self, and belief in one's ability to live a meaningful life (Bennetts, Pinches, Paluch, \& Fossey, 2013; Gordon \& Ellis, 2013; McCabe, Whittington, Cramond, \& Perkins, 2018; O’Hagan, 2012). The "recovery orientation" of services refers to the extent to which mental health staff and services attempt to facilitate or promote this philosophy of recovery. It also encompasses the different aspects of service delivery and practices that are believed to support recovery, including partnership, coproduction and shared decision making (Williams et al., 2012). A plethora of interventions, initiatives and service reconfigurations (Slade, 2013; Slade, Adams, \& O'Hagan, 2012; Slade et al., 2014) has consequently emerged, all aiming to fulfil the fundamental principles underpinning recovery. In moving towards recovery oriented mental health spaces, psychoeducation has emerged as one of the most commonly used psychosocial interventions (Mirsepassi, Tabatabaee, Sharifi, \& Mottaghipour, 2018).

Psychoeducation modalities range from individual and group models which are clinician or peer-led, to more recently, co-facilitated models (Tsiouri, Gena, Economou, Bonotis, \& Mouzas, 2015). They also vary in duration (brief $v s$. long) and format (online and face-to-face). In addition, variance exists in the diagnostic focus of psychoeducation, with some modalities focusing on a homogenous diagnosis and others encompassing heterogeneous diagnoses (Tsiouri et al., 2015). Across these varying modalities common objectives permeate: to increase service users' and/or their families' knowledge and understanding of specific mental health problems, to enhance their understanding of the available treatments; and to enhance their capacity to cope through the development of skills and the establishment of peer networks (Brady, Kangas, \& McGill, 2017).

An extensive research base supports the efficacy of psychoeducation for both service users and family members (Bond \& Anderson, 2015; Castle et al., 2010; Colom et al., 
2009; de Barros Pellegrinelli et al., 2013; Higgins et al., 2017; Michalak, Yatham, Wan, \& Lam, 2005). Psychoeducation delivered to service users has been shown to reduce their rate of relapse and rehospitalisation, especially if provided during an early phase of the mental health problem (Lucksted, McFarlane, Downing, \& Dixon, 2012; NICE, 2014; Stuart \& Schlosser, 2009; Vieta, 2005; Xia, Merinder, \& Belgamwar, 2011; Yesufu-Udechuku et al., 2015), and improve outpatient attendance and psychosocial functioning (Colom et al., 2003; Hunt, Siegfried, Morley, Sitharthan, \& Cleary, 2014; Pharoah, 2010; Tungpunkom \& Nicol, 2008; Xia et al., 2011; Zhao, Sampson, Xia, \& Jayaram, 2015). Aside from demonstrating its effectiveness on clinical outcomes, positive personal recovery outcomes have also been attributed to psychoeducation. These include increased hopefulness (Pickett et al., 2010), increased awareness of early warning signs and symptom triggers (Druss et al., 2010) and improved self-advocacy, empowerment and recovery (Barber, Rosenheck, Armstrong, \& Resnick, 2008; Bradley et al., 2006; Resnick \& Rosenheck, 2008).

Similarly, research evidence demonstrates the potential of psychoeducation programmes delivered to family members, to improve clinical outcomes for their relative experiencing mental health difficulties (Henken, Huibers, Churchill, Restifo, \& Roelofs, 2007; Jewell, Downing, \& McFarlane, 2009; Lucksted et al., 2012; McFarlane, Dixon, Lukens, \& Lucksted, 2003). A number of clinical trials (Bradley et al., 2006; Carrà, Montomoli, Clerici, \& Cazzullo, 2007; Kulhara, Chakrabarti, Avasthi, Sharma, \& Sharma, 2009; Magliano, Fiorillo, Malangone, De Rosa, Maj, Group, et al., 2006) and systematic reviews (Baucom, Shoham, Mueser, Daiuto, \& Stickle, 1998; Jewell et al., 2009; Murray-Swank \& Dixon, 2004; Rummel-Kluge \& Kissling, 2008; Taylor et al., 2009) have demonstrated how family psychoeducation can improve clinical outcomes for people experiencing schizophrenia and bipolar disorders, including reductions in symptomatic relapse and rehospitalisation. The outcomes of family psychoeducation are, however, not limited to service users' clinical outcomes. The inter-related nature of service user and family well-being is increasingly recognised. Consequently, there has been increased focus on the impact of psychoeducation on carer/family well-being (Lucksted et al., 2012). A systematic review by Sin, Henderson, Pinfold, and Norman (2013) of psychoeducational interventions for family members of people given a diagnosis of schizophrenia, indicates that family psychoeducation reduced carers' global morbidities, perceived burden and negative caregiving experiences, including expressed emotion. Similarly, positive outcomes have been found in relation to caregiver satisfaction, coping capacity and problem solving, as well as increased knowledge of mental illness, the mental health system and self-care (Dixon et al., 2004; Duckworth \& Halpern, 2014; Pickett-Schenk, Lippincott, Bennett, \& Steigman, 2008; Pickett-Schenk et al., 2006).

Despite the widespread recognition of its effectiveness, studies and reviews indicate that the successful implementation of psychoeducational interventions for individual families or service users has been limited and difficult to sustain.
This is reportedly due to multifaceted barriers at organisational, provider and service user levels (Brooke-Sumner et al., 2015; Caqueo-Urízar, Rus-Calafell, Urzúa, Escudero, \& Gutiérrez-Maldonado, 2015; Chakrabarti, 2011; Cohen et al., 2008; Dixon et al., 2001; Eassom, Giacco, Dirik, \& Priebe, 2014; Fadden, 1997; Glynn, Cohen, Dixon, \& Niv, 2005; Ince, Haddock, \& Tai, 2016; Magliano, Fiorillo, Malangone, De Rosa, \& Maj, 2006). This paper reports the findings of a review into the barriers and enablers influencing the implementation of group psychoeducation in mental health services. The review was conducted to inform the design and data collection of a research study into factors influencing the implementation of group psychoeducation for people experiencing mental health difficulties and their families.

\section{Methods}

The chosen methodological approach follows recommendations by Arksey and O'Malley (2005) and matches the third and fourth type of review identified in their typology of scoping reviews, in that, it aims to summarise findings as well as to identify gaps in the research literature. With the assistance of a Librarian, initial scoping searches using the database thesauri were run in Medline (EBSCO) (1965-), Embase (1990-), CINAHL Complete (1937-) and PsycINFO (1990-). These searches provided a list of synonyms using $\mathrm{MeSH}$ terms and CINAHL subject headings and PsycINFO descriptors and Emtree headings. This database spectrum ensured wide coverage of the literature ranging from journal articles to conference proceedings and monographs.

This was then followed by an analysis of the keywords, specifically words contained in the title and abstract and of the index terms used to describe the articles retrieved during the search. A double strand search strategy was applied running the thesauri terms first and then keywords. These two searches were then combined using the "OR" operator. This method was repeated for each concept and at the end the different concepts were combined together using "AND".

This strategy was initially created within Medline and then adapted for all other databases searched using keywords and database-specific subject headings, where applicable. Table 1 illustrates an exemplar of the search string utilized for one of the databases. No date restriction was applied and the search was completed in 2018.

A grey literature search encompassed an online search of research repositories and databases: Cochrane Library (http://www.cochranelibrary.com/); Open Grey (http://opengrey.eu/); Joanna Briggs Institute (JBI) Library of Systematic Reviews (http://joannabriggs.org); Organisation for Economic Co-operation and Development (OECD) (http:// www.oecd.org/); and Lenus - the Irish Health Repository (http://www.lenus.ie/hse/). In addition to searching the reference lists of the most relevant articles, a review of webbased resources of international organisations involved in mental health, such as MIND (www.mind.org.uk) and Mental Health Foundation (http://www.mentalhealth.org.uk) was also conducted. 
Table 1. Medline search strategy and results.

\begin{tabular}{|c|c|c|c|}
\hline$\#$ & Query & Limiters/Expanders & Results \\
\hline S9 & S1 AND S6 AND S7 & $\begin{array}{l}\text { Narrow by Subject Age: }- \text { all adult: } \\
19+\text { years Search modes - } \\
\text { Boolean/Phrase }\end{array}$ & 2613 \\
\hline S6 & S2 OR S4 & Search modes - Boolean/Phrase & 157,231 \\
\hline S5 & (MH "Mental Disorders+") & Search modes - Boolean/Phrase & $1,106,707$ \\
\hline S4 & (MH "Education") OR (MH "Program Evaluation+") & Search modes - Boolean/Phrase & 85,924 \\
\hline S2 & $\begin{array}{l}\text { TI (Workshop* OR "Training Program*" OR "Educational Activit*" OR *" OR "face to face" OR } \\
\text { "group session*" OR "peer support*" OR "group intervention*" OR psychoeducation* OR } \\
\text { psycho-education* OR "peer to peer" OR "programme development*" OR education* OR } \\
\text { instruction* OR teaching OR "program evaluation*") OR AB (Workshop* OR "Training } \\
\text { Program*" OR "Educational Activit*" OR *" OR "face to face" OR "group session*" OR "peer } \\
\text { support*" OR "group intervention*" OR psychoeducation* OR psycho-education* OR "peer } \\
\text { to peer" OR "programme development*" OR education* OR instruction* OR teaching OR } \\
\text { "program evaluation*") }\end{array}$ & Search modes - Boolean/Phrase & 79,938 \\
\hline
\end{tabular}

\section{Screening articles for inclusion}

The Covidence software package (www.covidence.org/) was used to manage the screening and selection process. To be included in this review, studies had to: (a) be empirically researched; (b) focus on psychoeducation for adults $(>18)$ with mental health problems and/or their families; (c) be conducted in a group format in the mental health services; (d) be in English; (e) provide evidence on barriers and enablers to the implementation and sustainability of the educational initiatives; and/or (f) provide information on the strategies for overcoming such barriers. Studies not meeting these criteria were excluded.

A two-stage screening process was employed to assess the relevance of research studies identified. Firstly, the titles and abstracts for 9129 records were independently assessed by two reviewers and inclusion and exclusion criteria applied. Any discrepancies were resolved by involvement and discussion with a third reviewer. The title and abstract screen eliminated 8969 records, leaving 160 articles for full review. For stage two, two reviewers each noting their reasons for a paper's exclusion, independently screened 160 full-text articles and a third reviewer resolved any conflicts. Two authors were contacted to secure further information about the format and target audience of the psychoeducation described in their articles. These papers were subsequently excluded on receipt of that information. In total, eight papers were included in the review. Figure 1 provides a visual representation of the review's methodological process, which followed the PRISMA framework and includes reasons why 152 of the 160 articles were excluded. The review protocol was not published on Prospero.

\section{Data extraction and analysis}

To assist with data extraction, a data extraction template was developed and piloted. Data extracted included the study design, participants' profile, study setting, intervention design, barriers to implementation, enablers to implementation and strategies to support implementation. Three reviewers independently extracted data, which were then cross-checked. Inconsistencies were discussed and agreement reached. Once the data were extracted, a two-stage process of analysis was performed. First findings from each paper were coded, compared and grouped into barriers and enablers. Following this, using Chaudoir, Dugan, and Barr's (2013) framework as a template for analysis, the barriers and enablers were recoded and ordered (Chaudoir et al., 2013). Chaudoir et al. (2013) framework was selected as it provided a useful way of comparing commonalities and differences across studies that were heterogeneous. In addition, by conceptualising barriers and enablers at five levels, it facilitated the researcher to identify if there were gaps in knowledge in relation to the barriers and enablers. The five levels of the framework are the participant level (patient/ family health related beliefs, motivation, personality traits, health literacy); the provider level (knowledge and beliefs about intervention, self-efficacy and readiness); the intervention or innovation level (components, degree of adaptability permitted, strength of evidence, degree of planning, engaging people); the organisational/inner level (cultural, leadership, organisational capacity); and the structural level (economic, political, policy, social and infrastructural context). In completing this aspect of the analysis, the reviewers were aware that the boundaries between levels are not fixed 

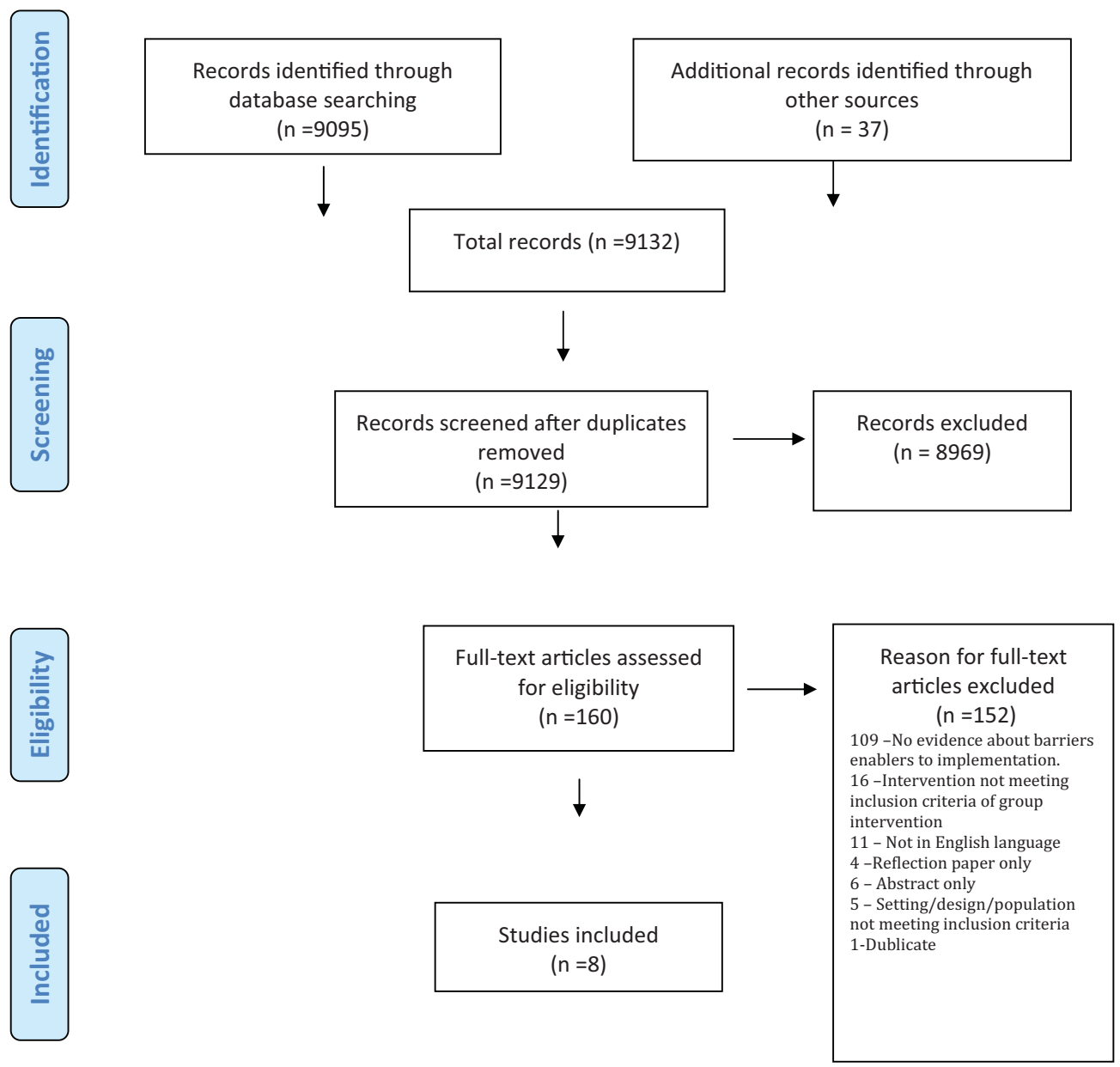

Figure 1. PRISMA flow diagram.

and they therefore endeavoured to reduce interpretative bias via in-depth discussions throughout the analytical process.

\section{Quality}

All articles that met eligibility criteria were assessed for quality. Studies were assigned a grade 1-4 $(1=$ Very poor; $4=$ Good) using the 9-item tool devised by Hawker, Payne, Kerr, Hardey, and Powell (2002). Two rounds of reviewing took place with each article reviewed independently by two researchers. This ensured rigour of grade assignment and allowed for an assessment of the inter-rater reliability of the grading scheme. Disagreement between authors was resolved by consensus. Only three studies had very few methodological limitations (Ingvarsdotter, Persson, Hjärthag, \& Östman, 2016; Sherman \& Fischer, 2012; Whitley, Gingerich, Lutz, \& Mueser, 2009). The absence of information regarding sampling (Coulthard, Patel, Brizzolara, Morriss, \& Watson, 2013; Hackethal et al., 2013; Poole, Smith, \& Simpson, 2015), data analysis and ethical procedures (Coulthard et al., 2013; Hackethal et al., 2013; Petrakis, Bloom, \& Oxley, 2014; Poole et al., 2015; Sherman et al., 2009; Sherman \& Fischer, 2012) resulted in the remaining studies receiving a lower quality assessment grade (Table 2).

\section{Findings}

\section{Characteristics of the included studies}

Two of the psychoeducation programmes described focused on both family members and service users (Hackethal et al., 2013; Ingvarsdotter et al., 2016), three concentrated on service-users only (Coulthard et al., 2013; Poole et al., 2015; Whitley et al., 2009) and three programmes centered on family members only (Petrakis et al., 2014; Sherman et al., 2009; Sherman \& Fischer, 2012). The psychoeducation programmes were developed for those affected by a diagnosis of bipolar (Coulthard et al., 2013; Poole et al., 2015), schizophrenia (Hackethal et al., 2013), first episode of psychosis $(n=1)$ (Petrakis et al., 2014), "serious mental illness" (Ingvarsdotter et al., 2016; Sherman \& Fischer., 2012; Whitley et al., 2009) and major depressive disorder, bipolar and/or PTSD (Sherman et al., 2009). The psychoeducation programmes were predominantly facilitated by clinicians $(n=4)$, with one programme being co-facilitated by clinicians and service user peers (Coulthard et al., 2013). Three articles provided no information on who facilitated the programme (Hackethal et al., 2013; Sherman et al., 2009; Whitley et al., 2009).

Six of the eight included studies employed qualitative methods (Hackethal et al., 2013; Ingvarsdotter et al., 2016; Poole et al., 2015; Sherman et al., 2009; Sherman \& Fischer, 
JOURNAL OF MENTAL HEALTH -5

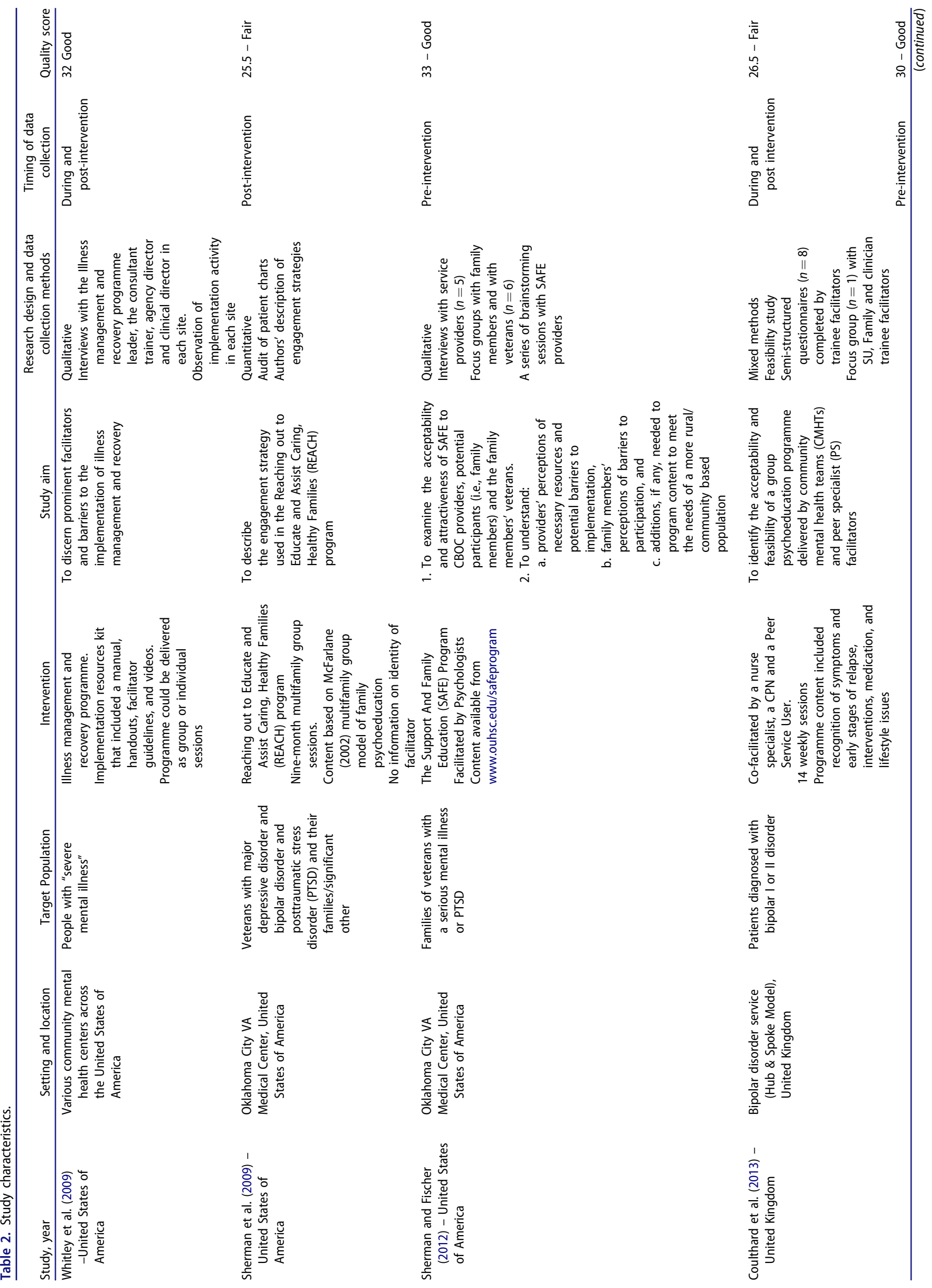




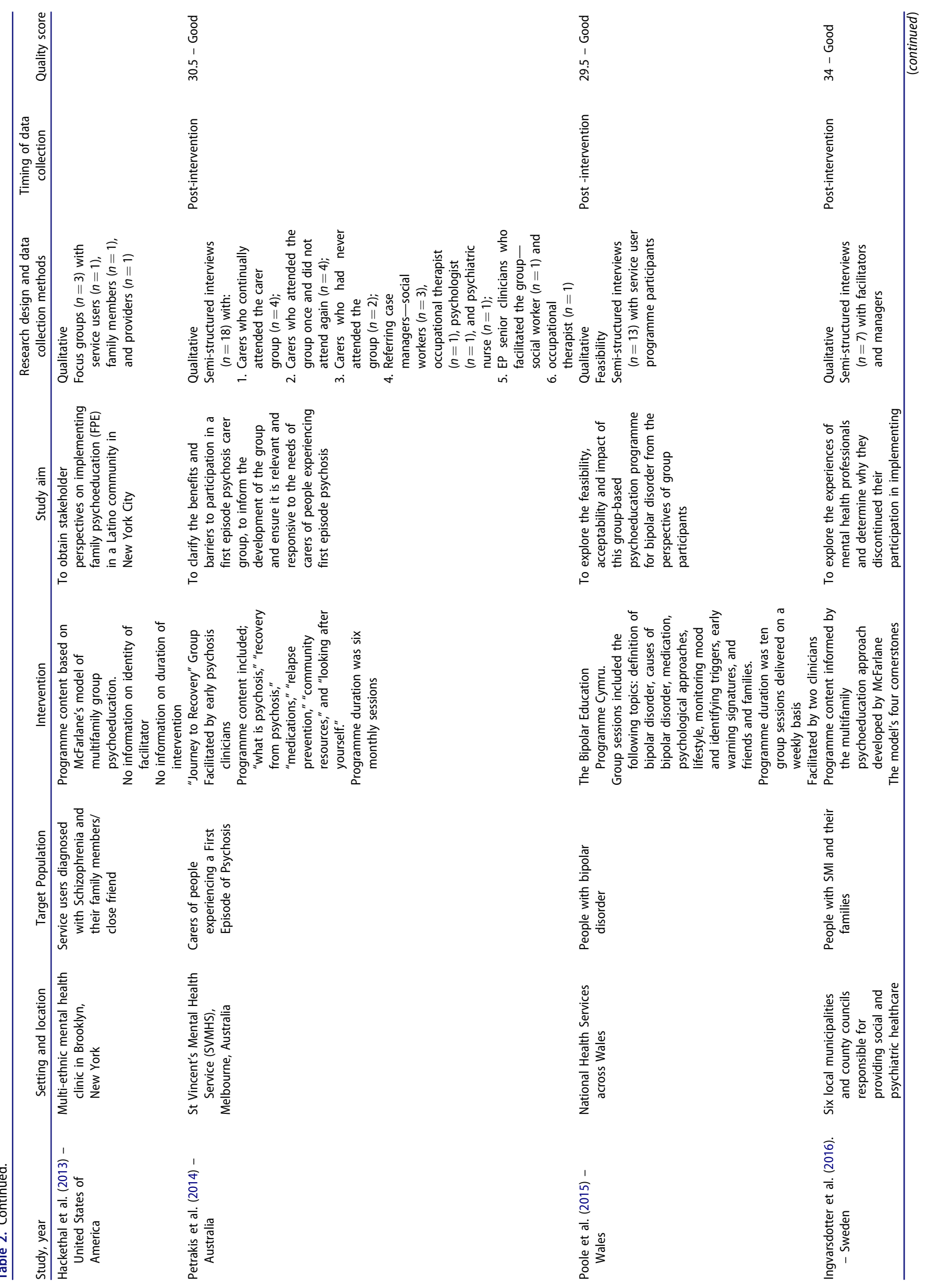


2012; Whitley et al., 2009), one of the studies utilised quantitative methods (Sherman et al., 2009) and one used mixed methods (Coulthard et al., 2013). Data on barriers and enablers were elicited from clinical facilitators/programme leader (Coulthard et al., 2013; Ingvarsdotter et al., 2016; Sherman \& Fischer, 2012; Whitley et al., 2009), peer facilitators (Coulthard et al., 2013), service users (Poole et al., 2015), family members (Sherman \& Fischer, 2012), clinical and agency directors (Whitley et al., 2009), consultant trainers (Whitley et al., 2009) and an audit of patient charts (Sherman et al., 2009).

The time of data collection also varied; data were collected prior to the intervention (Hackethal et al., 2013; Sherman \& Fischer, 2012), post-intervention (Ingvarsdotter et al., 2016; Petrakis et al., 2014; Poole et al., 2015; Sherman et al., 2009; Whitley et al., 2009) and during the intervention (Coulthard et al., 2013; Whitley et al., 2009). The included studies were conducted in the USA $(n=4)$, United Kingdom $(n=2)$, Sweden $(n=1)$ and Australia $(n=1)$. Table 2 presents detailed accounts of the eight studies, including the results of the quality appraisal.

\section{Themes}

This review is based on the final sample of eight articles, each of which provided empirical evidence on the barriers and enablers to implementing recovery focused group psychoeducation in adult mental health services.

\section{Barriers to implementation}

Data analysis identified that barriers to implementation occurred at all five levels of Chaudoir et al.'s (2013) framework: participant; practitioner; intervention; organisational; and structural level (See Table 3).

\section{Participant level barriers (service user/family member)}

Five papers reported barriers in relation to family members or service users attending a group psychoeducation intervention (Hackethal et al., 2013; Ingvarsdotter et al., 2016; Petrakis et al., 2014; Poole et al., 2015; Sherman \& Fischer, 2012). Service users reported that their mood negatively affected their capacity to attend or if attending, the quality of their participation suffered because of poor motivation and concentration (Poole et al., 2015). Family informants described discomfort with group social situations and found it challenging to reveal and communicate emotions, as well as to hear about the emotions of others (Petrakis et al., 2014).

In a paper that discussed a conjoint programme for service users and family members, service users reported that as their familial relationships had deteriorated they did not have a family member that they could ask to join them in participation (Ingvarsdotter et al., 2016). Informants (both family and service user) in Sherman and Fischer's (2012) study also focused on familial relationships. Family members emphasised the difficulty of attending in cases where 
Table 3. Barriers and facilitators.

\begin{tabular}{|c|c|c|}
\hline Levels & Barriers & Enablers \\
\hline Participant & $\begin{array}{l}\text { Service user } \\
\text { - } \quad \text { Mood } \\
\text { - } \text { Familial dynamics } \\
\text { - } \text { Stigma } \\
\text { - Competing demands } \\
\text { Family member } \\
\text { - } \quad \text { Discomfort with group format } \\
\text { - Familial dynamics } \\
\text { - Stigma } \\
\text { - } \quad \text { Competing demands }\end{array}$ & $\begin{array}{l}\text { Service user and family members } \\
\text { - Format of intervention that provided opportunity to share } \\
\text { experiences, learn from each other and engage socially }\end{array}$ \\
\hline Provider & $\begin{array}{l}\text { Clinical facilitators } \\
\text { - Challenges negotiating workload } \\
\text { - Skills deficits } \\
\text { - Lack of support } \\
\text { - Perception of benefit to attendees } \\
\text { Peer facilitators } \\
\text { - Financial reimbursement } \\
\text { - Lack of support }\end{array}$ & $\begin{array}{l}\text { - Positive attitudes to developing expertise in recovery oriented } \\
\text { and consumer oriented approaches } \\
\text { - Presence of a peer facilitator } \\
\text { - Facilitator skill }\end{array}$ \\
\hline Organisation & $\begin{array}{l}\text { - Leadership deficits across the mental health system state/ } \\
\text { service/centre/programme level } \\
\text { - } \quad \text { Planning deficits } \\
\text { - } \text { Managerial support deficits } \\
\text { - Resource deficits (securing long terms funding and venue) } \\
\text { Resistance within organisation }\end{array}$ & $\begin{array}{l}\text { - Leadership across the mental health system state/service/centre/ } \\
\text { programme level) that championed the intervention } \\
\text { - Strong culture of innovation } \\
\text { - } \text { Allocation of extra personnel } \\
\text { - } \text { Managerial support } \\
\text { - Clear communication between stakeholders }\end{array}$ \\
\hline Structural & - Cost and reliability of public transport & \\
\hline
\end{tabular}

their relative with mental health difficulties was opposed to it. Consequently, they feared attendance might have a negative impact on their relationships, including conflict and disruption of family roles/identities.

In addition to concerns about the impact on family relationships, service users also worried about confidentiality should their family member attend a group, fearing "rumours" outside the group about content disclosed (Sherman \& Fischer, 2012). In two papers (Hackethal et al., 2013; Sherman \& Fischer, 2012), stigma and fear of others finding out about their own or their family member's mental health problems appeared to deter participation. A number of family members in Petrakis et al's (2014) study were also of the view that their "experiences are private family matters" and not for discussion outside of the family. In Sherman and Fischer's (2012) study, staff informants also mentioned that stigma would discourage rural families in particular from attending, as they perceived these families to be "less open minded about mental health".

Competing demands, such as work and family commitments were particular issues for family members, with clashing medical appointments affecting service users' availability to attend (Hackethal et al., 2013; Petrakis et al., 2014; Poole et al., 2015; Sherman \& Fischer, 2012).

\section{Provider level barriers}

Provider-related barriers included staff attitudes, deficits in time, support and skills. Staff being uninterested in learning new practices, as well as being unconvinced of the benefits and efficacy of illness management or recovery oriented interventions were identified as a barrier in Whitley et al.'s (2009) study. Time to implement the intervention was a barrier in three studies, as large caseloads made existing schedules busy (Coulthard et al., 2013; Ingvarsdotter et al., 2016; Sherman \& Fischer, 2012) and clinicians were not always able to fit the intervention into the usual structure of services (Ingvarsdotter et al., 2016). Clinical informants reported that negotiating reduced caseloads, asking colleagues to cover their workload or allocating tasks to colleagues was not an option (Coulthard et al., 2013; Ingvarsdotter et al., 2016). Consequently, some practitioners terminated their participation in the intervention (Coulthard et al., 2013).

Informants in two studies also reported that the significant amount of time invested was not proportional to the impact (Whitley et al., 2009; Ingvarsdotter et al., 2016), as only a small number of family members could attend a group (Ingvarsdotter et al., 2016). In three studies, deficits in skills and training hindered implementation (Coulthard et al., 2013; Ingvarsdotter et al., 2016; Sherman \& Fischer, 2012), with providers requesting further training (Coulthard et al., 2013) and ongoing support for the duration of the intervention (Sherman \& Fischer, 2012).

Peer providers identified barriers related to support and financial reimbursement. In Coulthard et al.'s (2013) study, the peer facilitators felt unsupported and isolated because of their dual identity as patient and staff member. They also reported feeling particularly unsupported and vulnerable during times of ill health and during the training process. 
In addition, peer facilitators had concerns that payments for facilitating would have a detrimental impact on their social security payments, with some reporting experiencing delays in receiving payments (Coulthard et al., 2013).

\section{Intervention level barriers}

Five papers reported barriers in relation to the intervention (Hackethal et al., 2013; Ingvarsdotter et al., 2016; Petrakis et al., 2014; Poole et al., 2015; Sherman \& Fischer, 2012). The lack of content specifically tailored to participants' ages, diagnoses and cultures attracted concern (Hackethal et al., 2013; Ingvarsdotter et al., 2016; Petrakis et al., 2014), with some informants perceiving the content as too generic (Ingvarsdotter et al., 2016; Petrakis et al., 2014) or the differences in the age profile of the group attendees as a barrier (Poole et al., 2015).

Other issues that affected acceptability were the style and skill of the facilitator (Ingvarsdotter et al., 2016; Poole et al., 2015). Specifically identified as problematic was the facilitators' management of time, content and group dynamics. Digression from discussion foci, absence of equal participation from all group members and unimpeded group conflicts were among the frustrations identified (Poole et al., 2015). In addition, service users reported that at times they felt patronized, "talked at", disempowered and/or under pressure to contribute, especially when facilitators directed questions to individuals (Poole et al., 2015). Other service users reported feeling intimidated and pressurised by the group format itself, with the personality and behavioural traits of group members inducing discomfort (Poole et al., 2015).

Four papers identified accessibility to the intervention as a barrier to attendance and retention (Hackethal et al., 2013; Petrakis et al., 2014; Poole et al., 2015; Sherman \& Fischer, 2012). In three studies, the timing of sessions acted as a barrier to attendance (Hackethal et al., 2013; Petrakis et al., 2014; Poole et al., 2015). The risk of encountering dangers at night discouraged some participants from venturing out to an evening session (Hackethal et al., 2013), with informants split in their preferences for morning or afternoon/ evening sessions (Petrakis et al., 2014; Poole et al., 2015).

The location of sessions was problematic in three studies (Petrakis et al., 2014; Poole et al., 2015; Sherman \& Fischer, 2012). Although the exact problem was not explicit in Petrakis et al.'s (2014) study, in both Poole et al.'s (2015) and Sherman and Fischer's (2012) studies the issue was travel distance. In addition, service users in Poole et al.'s (2015) study deemed a hospital setting as undesirable because it evoked negative memories.

Only one study reported aspects of the recruitment process to be a barrier. In particular, one participant in Poole et al.'s (2015) paper perceived the invitation letter to be intimidating, too formal in tone and lacking in specifics about the format of the course. In one paper, clinician facilitators reported that the programme guidelines on how to manage communication and discussions within the group lacked flexibility. In addition, the guidelines were reported to be overly restrictive, which affected the clinicians' acceptability of the programme (Ingvarsdotter et al., 2016).

\section{Organisational level barriers}

In total, six organisational level barriers were identified: lack of leadership; planning; managerial support; difficulty locating space; administrative support; and difficulties with financial reimbursement. In Whitley et al.'s (2009) study, leadership deficits across the entire mental health system was identified as the strongest barrier in the low fidelity sites. These sites were also characterised as having no history of innovation which contributed to organisational inertia.

In Ingvarsdotter et al.'s (2016) study, planning deficits specifically in relation to integrating the intervention into the wider system of care, as well as an absence of clarity around lines of communication and participant recruitment, meant practitioners were unsure of process and lines of responsibility. In two papers, a deficit in support from management was an issue in relation to securing long-term funding (Coulthard et al., 2013) and in combatting resistance or supporting those who feared change (Ingvarsdotter et al., 2016). One study also reported difficulties in securing physical space or space large enough to accommodate a group (Sherman \& Fischer, 2012) and one reported a lack of administrative support as a barrier (Coulthard et al., 2013).

\section{Structural level barriers}

Structural-level barriers refer to factors in the external sociocultural context or community in which a specific organization is nested. Three papers cited infrastructure as an issue, with informants reporting the cost and reliability of public transport and the limited availability of private transport as barriers to attendance (Hackethal et al., 2013; Petrakis et al., 2014; Sherman \& Fischer, 2012).

\section{Enablers to implementation}

From the analysis, enablers were identified at four levels of Chaudoir et al.'s (2013) framework: participant; provider; intervention; and organisational level (see Table 3).

\section{Participant level enablers (service user/family)}

Individuals' acceptability of the group format assisted implementation (Ingvarsdotter et al., 2016; Poole et al., 2015). For example, some family members and service users cited the opportunity to share experiences and learn with and from other group members as particularly valuable, appealing and therapeutic. In addition, the opportunity to engage socially with others enhanced acceptability for some participants.

\section{Provider level enablers}

Staff who were committed to service users' wellbeing and recovery, eager to learn new ways of working and/or had a positive attitude towards recovery and service user centred 
interventions were identified as enablers (Whitley et al., 2009). Another enabler that was identified, included the presence of a peer facilitator, which reduced anxiety amongst participants and assisted in creating a friendly and comfortable atmosphere (Coulthard et al., 2013). Facilitators' style and skill was also addressed. Facilitators who created a relaxed and informal environment, answered attendees' questions, listened to and valued their point of view and made them feel accepted, were found to enhance acceptability (Poole et al., 2015).

\section{Intervention level enablers}

Five papers (Coulthard et al., 2013; Hackethal et al., 2013; Ingvarsdotter et al., 2016; Petrakis et al., 2014; Poole et al., 2015) discussed enablers related to the content, delivery and format of the intervention. Informants in each of these five studies described components, which they perceived facilitated acceptability of the intervention. The creation of friendly, sociable spaces (Hackethal et al., 2013; Poole et al., 2015) that were centrally located in community venues were deemed helpful (Poole et al., 2015). Informants cited content that was clear, succinct and relevant as key factors in the successful implementation of programmes (Hackethal et al., 2013; Petrakis et al., 2014; Poole et al., 2015). Participants in Poole et al.'s (2015) study specifically commented positively on the availability of written handouts, the use of mood diaries and the provision of information on medication in pregnancy and contact information for crisis support services.

In relation to recruitment of service user/family member participants, informants in three studies noted that successful recruitment was dependent upon ongoing engagement with the person to build rapport and trust and incrementally work on their motivation to attend (Hackethal et al., 2013; Ingvarsdotter et al., 2016; Sherman et al., 2009). In Sherman et al.'s (2009) study, clinicians invested significant time in educating service users and family members about the intervention. During the first engagement session, service users received information about the intervention, including information on confidentiality. Using a programme checklist, the clinician facilitated the person to express their goals for involvement and using motivational interviewing, supported them to weigh the advantages and disadvantages of attending. Sherman et al. (2009) also reported asking family members about their schedules and using this information to ensure the programme was responsive to their needs and schedules.

Three papers highlighted the importance of engaging continually with clinician providers to secure their involvement (Petrakis et al., 2014; Poole et al., 2015; Sherman et al., 2009). Strategies used included: the regular hosting of presentations to inform clinicians about the intervention (Petrakis et al., 2014; Poole et al., 2015; Sherman et al., 2009); reviewing charts to identify suitable participants; providing laminated sheets that explained the referral process; monitoring weekly trends in referrals; providing opportunities to problem solve around obstacles; acknowledging clinicians who referred the largest number of participants; and hosting an appreciation luncheon to provide feedback on progress (Sherman et al., 2009).

\section{Organisational level enablers}

Only three papers discussed organisational enablers which supported implementation (Coulthard et al., 2013; Sherman et al., 2009; Whitley et al., 2009). Whitley et al. (2009) reported the centrality of synergistic leadership across mental health services at state, agency and programme levels, as "strong leadership at higher levels generally permeated down to leaders at lower levels" (p. 206). In addition to leadership, a culture of innovation, positive attitudes to new practices, a history of successful implementation of innovations, as well as the provision of high quality training and support during the early phase of implementation were identified as enablers (Whitley et al., 2009).

Two papers highlighted the importance of adequate managerial support, as well as resource allocation (Coulthard et al., 2013; Sherman et al., 2009). The appointment of an additional peer facilitator eased anxiety about absences due to illness. In addition, the appointment of a nurse specialist provided additional support to practitioner and peer facilitators with the implementation (Coulthard et al., 2013). Clear communication between key stakeholders, as well as having strategies in place to share information around challenges was also cited as an enabler (Coulthard et al., 2013).

\section{Discussion}

Every year money is invested around the world in the development and evaluation of evidence based health care interventions, yet only a fraction of these interventions ever get translated into practice (Chaudoir et al., 2013). The situation is similar in the area of mental health. Despite the evidence base to support the efficacy of psychoeducation (Brady et al., 2017; Sin et al., 2017; Tribe, Sendt, \& Tracy, 2019; Xia et al., 2011; Yesufu-Udechuku et al., 2015; Zhao et al., 2015) and the numerous policy and guideline recommendations regarding the importance of psychoeducation (Dixon et al., 2010; Goodwin \& Consensus Group of the British Association for Psychopharmacology, 2009; NICE, 2014; SAMHSA, 2001), many service users and family members still do not have access to such programmes (Eassom et al., 2014). Gaps in our understanding of the factors that have an impact on implementation present a significant barrier to ensuring equity of access. This review begins the process of filling this gap by synthesizing the evidence from the admittedly small number of available peer-reviewed studies on the barriers and enablers to implementation of group psychoeducation. A number of the influencing factors identified in this review are similar to barriers and enablers reported in studies on psychological interventions aimed at the individual service user/family unit, such as leadership, staff attitudes, staff skill level, recruitment challenges and time (Fadden, 1997; Ince et al., 2016; Kuller, Ott, Goisman, Wainwright, \& Rabin, 2010; Magliano, Fiorillo, Malangone, De Rosa, \& Maj, 2006). However, this review also highlights barriers that are unique to the group context, such as 
participant concerns about stigma and confidentiality, providers' ability to manage group dynamics and locate appropriate accommodation, as well as financial reimbursement and support for peer facilitators.

Many implementation theories and frameworks have been described in the literature (Berkel, Mauricio, Schoenfelder, \& Sandler, 2011; Chaudoir et al., 2013; Durlak \& DuPre, 2008), yet none of these models or frameworks were used to underpin the studies referred to in this review. The absence of a theoretical model or framework to guide the studies may be an indication of the underdeveloped state of implementation science in this area. It may also be due to a belief that "theory is not necessarily better than common sense for guiding implementation" (Nilsen, 2015). Irrespective of the reasons, their absence has resulted in a lack of cohesion in the evidence produced, with many possible issues left unexplored. Although some of the findings from our review correspond to Chaudoir et al.'s (2013) five levels, there are some notable absences that require addressing in future studies. Future studies need to address the impact of wider structural factors (mental health policy, economic or social factors) and intervention level factors (clinical guidelines or strength of evidence) on implementation. In addition, there is a need for studies that explore the interrelationship between the various factors and levels. Given the dearth of evidence around strategies to minimize obstacles and barriers there is also a need for studies that explore strategies to enhance implementation.

While there is some consistency in the enablers and barriers, the small sample sizes, the convenience nature of the sampling, the diverse range of settings internationally and the fact that some of the factors were only reported in one or two studies, limits the generalisability of the findings beyond the context of the studies included. In addition, the heterogeneity among the target audience for the intervention (service users/family) as well as combining peer or professionally led interventions may have obscured subtle differences between groups, which may be critical in moving the field forward. In addition, many of the studies relied on subjective, self-report measures, with the majority of studies collecting data prior to or immediately post intervention. Thus, future studies need to address factors affecting long-term sustainability.

Although the authors searched a number of databases, undertook the review systematically and ensured that the three reviewers conducted the screening, quality appraisal, data extraction and data analysis independently, the review has a number of other limitations that need consideration. Only studies published in the English language in peerreviewed journals were included, potentially introducing publication bias. As the review was designed to include all relevant research in order to provide a broad evidence base on the barriers and enablers, the quality appraisal undertaken was not used to exclude studies. Thus, studies that had lower ratings on quality were included.

\section{Conclusion}

Implementing evidence-based group psychoeducation interventions is a complex process as a broad range of factors across multiple levels affect implementation outcomes. While there is some degree of variability in relation to the factors identified within this review, the findings provide preliminary information to practitioners, managers, policy makers and researchers involved in the design, implementation and evaluation of group psychoeducation programmes. However, there is a need for more robust larger-scale studies into factors impacting implementation and sustainability that are informed by implementation theories and studies that address the potential impact of different models of intervention, as well as the target audience. In addition to studies into implementation processes and outcomes, there is a need for studies that explore the interrelationships between the various levels of enablers and barriers identified. Without this form of evidence, it is unlikely that interventions like group psychoeducation will be added and embedded as a treatment option across all mental health services.

\section{Disclosure statement}

The authors have no other conflicts of interest to declare.

\section{Funding}

The review was funded by a grant from the Health Research Board Ireland in partnership with the Health Service Executive through the Applied Partnership Award scheme. The review is part of a larger study into factors influencing implementation and sustainability of group psychoeducation interventions [Grant number APA-206-1858].

\section{ORCID}

Thilo Kroll (D) http://orcid.org/0000-0003-2082-5117

David Hevey (ID) http://orcid.org/0000-0003-2844-0449

Louise Doyle (iD http://orcid.org/0000-0002-0153-8326

\section{References}

Arksey, H., \& O'Malley, L. (2005). Scoping studies: Towards a methodological framework. International Journal of Social Research Methodology, 8(1), 19-32. doi:10.1080/1364557032000119616

Barber, J. A., Rosenheck, R. A., Armstrong, M., \& Resnick, S. G. (2008). Monitoring the dissemination of peer support in the VA Healthcare System. Community Mental Health Journal, 44(6), 433-441. doi:10.1007/s10597-008-9146-7

Baucom, D. H., Shoham, V., Mueser, K. T., Daiuto, A. D., \& Stickle, T. R. (1998). Empirically supported couple and family interventions for marital distress and adult mental health problems. Journal of Consulting and Clinical Psychology, 66(1), 53-88. doi:10.1037/0022006X.66.1.53

Bennetts, W., Pinches, A., Paluch, T., \& Fossey, E. (2013). Real lives, real jobs: Sustaining consumer perspective work in the mental health sector. Advances in Mental Health, 11(3), 313-325. doi:10. 5172/jamh.2013.11.3.313

Berkel, C., Mauricio, A. M., Schoenfelder, E., \& Sandler, I. N. (2011). Putting the pieces together: An integrated model of program implementation. Prevention Science, 12(1), 23-33. doi:10.1007/s11121-0100186-1

Bond, K., \& Anderson, I. M. (2015). Psychoeducation for relapse prevention in bipolar disorder: A systematic review of efficacy in 
randomized controlled trials. Bipolar Disorders, 17(4), 349-362. doi: 10.1111/bdi.12287

Bradley, G. M., Couchman, G. M., Perlesz, A., Nguyen, A. T., Singh, B., \& Riess, C. (2006). Multiple-family group treatment for English-and Vietnamese-speaking families living with schizophrenia. Psychiatric Services, 57(4), 521-530. doi:10.1176/ps.2006.57.4.521

Brady, P., Kangas, M., \& McGill, K. (2017). "Family Matters": A systematic review of the evidence for family psychoeducation for major depressive disorder. Journal of Marital and Family Therapy, 43(2), 245-263. doi:10.1111/jmft.12204

Brooke-Sumner, C., Petersen, I., Asher, L., Mall, S., Egbe, C. O., \& Lund, C. (2015). Systematic review of feasibility and acceptability of psychosocial interventions for schizophrenia in low and middle income countries. BMC Psychiatry, 15(1), 19. doi:10.1186/s12888015-0400-6

Caqueo-Urízar, A., Rus-Calafell, M., Urzúa, A., Escudero, J., \& Gutiérrez-Maldonado, J. (2015). The role of family therapy in the management of schizophrenia: Challenges and solutions. Neuropsychiatric Disease and Treatment, 11, 145-151. doi:10.2147/ ndt.s51331

Carrà, G., Montomoli, C., Clerici, M., \& Cazzullo, C. L. (2007). Family interventions for schizophrenia in Italy: Randomized controlled trial. European Archives of Psychiatry and Clinical Neuroscience, 257(1), 23-30. doi:10.1007/s00406-006-0677-z

Castle, D., White, C., Chamberlain, J., Berk, M., Berk, L., Lauder, S., ... Gilbert, M. (2010). Group-based psychosocial intervention for bipolar disorder: Randomised controlled trial. British Journal of Psychiatry, 196(5), 383-388. doi:10.1192/bjp.bp.108.058263

Chakrabarti, S. (2011). Family interventions in schizophrenia: Issues of relevance for Asian countries. World Journal of Psychiatry, 1(1), 4-7. doi:10.5498/wjp.v1.i1.4

Chaudoir, S. R., Dugan, A. G., \& Barr, C. H. (2013). Measuring factors affecting implementation of health innovations: A systematic review of structural, organizational, provider, patient, and innovation level measures. Implementation Science, 8(1), 22. doi:10.1186/1748-59088-22

Cohen, A. N., Glynn, S. M., Murray-Swank, A. B., Barrio, C., Fischer, E. P., McCutcheon, S. J., ... Dixon, L. B. (2008). The family forum: Directions for the implementation of family psychoeducation for severe mental illness. Psychiatric Services, 59(1), 40-48. doi:10.1176/ ps.2008.59.1.40

Colom, F., Vieta, E., Martínez-Arán, A., Reinares, M., Goikolea, J. M., Benabarre, A., ... Corominas, J. (2003). A randomized trial on the efficacy of group psychoeducation in the prophylaxis of recurrences in bipolar patients whose disease is in remission. Archives of General Psychiatry, 60(4), 402-407. doi:10.1001/archpsyc.60.4.402

Colom, F., Vieta, E., Sánchez-Moreno, J., Goikolea, J. M., Popova, E., Bonnin, C. M., \& Scott, J. (2009). Psychoeducation for bipolar II disorder: An exploratory, 5-year outcome subanalysis. Journal of Affective Disorders, 112(1-3), 30-35. doi:10.1016/j.jad.2008.03.023

Coulthard, K., Patel, D., Brizzolara, C., Morriss, R., \& Watson, S. (2013). A feasibility study of expert patient and community mental health team led bipolar psychoeducation groups: Implementing an evidence based practice. BMC Psychiatry, 13(1), 301. doi:10.1186/ 1471-244X-13-301

de Barros Pellegrinelli, K., de O. Costa, L. F., Silval, K. I. D., Dias, V. V., Roso, M. C., Bandeira, M., ... Moreno, R. A. (2013). Efficacy of psychoeducation on symptomatic and functional recovery in bipolar disorder. Acta Psychiatrica Scandinavica, 127(2), 153-158. doi:10.1111/acps.12007

Dixon, L. B., Dickerson, F., Bellack, A. S., Bennett, M., Dickinson, D., Goldberg, R. W., ... Kreyenbuhl, J. (2010). The 2009 schizophrenia PORT psychosocial treatment recommendations and summary statements. Schizophrenia Bulletin, 36(1), 48-70. doi:10.1093/schbul/ $\operatorname{sbp} 115$

Dixon, L., Lucksted, A., Stewart, B., Burland, J., Brown, C. H., Postrado, L., ... Hoffman, M. (2004). Outcomes of the peer-taught 12 -week family-to-family education program for severe mental illness. Acta Psychiatrica Scandinavica, 109(3), 207-215. doi:10.1046/j. 0001-690X.2003.00242.x
Dixon, L., McFarlane, W. R., Lefley, H., Lucksted, A., Cohen, M., Falloon, I., ... Sondheimer, D. (2001). Evidence-based practices for services to families of people with psychiatric disabilities. Psychiatric Services, 52(7), 903-910. doi:10.1176/appi.ps.52.7.903

Druss, B. G., Zhao, L., von Esenwein, S. A., Bona, J. R., Fricks, L., Jenkins-Tucker, S., ... Lorig, K. (2010). The Health and Recovery Peer (HARP) Program: A peer-led intervention to improve medical self-management for persons with serious mental illness. Schizophrenia Research, 118(1-3), 264-270. doi:10.1016/j.schres.2010. 01.026

Duckworth, K., \& Halpern, L. (2014). Peer support and peer-led family support for persons living with schizophrenia. Current Opinion in Psychiatry, 27(3), 216-221. doi:10.1097/YCO.0000000000000051

Durlak, J. A., \& DuPre, E. P. (2008). Implementation matters: A review of research on the influence of implementation on program out comes and the factors affecting implementation. American Journal of Community Psychology, 41(3-4), 327-350. doi:10.1007/s10464008-9165-0

Eassom, E., Giacco, D., Dirik, A., \& Priebe, S. (2014). Implementing family involvement in the treatment of patients with psychosis: A systematic review of facilitating and hindering factors. BMJ Open, 4(10), e006108. doi:10.1136/bmjopen-2014-006108

Fadden, G. (1997). Implementation of family interventions in routine clinical practice following staff training programs: A major cause for concern. Journal of Mental Health, 6(6), 599-612. doi:10.1080/ 09638239718464

Glynn, S. M., Cohen, A. N., Dixon, L. B., \& Niv, N. (2005). The potential impact of the recovery movement on family interventions for schizophrenia: Opportunities and obstacles. Schizophrenia Bulletin, 32(3), 451-463. doi:10.1093/schbul/sbj066

Goodwin, G.M, Consensus Group of the British Association for Psychopharmacology. (2009). Evidence-based guidelines for treating bipolar disorder: Revised second edition - Recommendations from the British Association for Psychopharmacology. Journal of Psychopharmacology, 23(4), 346-388. doi:10.1177/0269881109102919

Gordon, S. E., \& Ellis, P. M. (2013). Recovery of evidence-based practice. International Journal of Mental Health Nursing, 22(1), 3-14. doi:10.1111/j.1447-0349.2012.00835.x

Hackethal, V., Spiegel, S., Lewis-Fernández, R., Kealey, E., Salerno, A., \& Finnerty, M. (2013). Towards a cultural adaptation of family psychoeducation: Findings from three Latino focus groups. Community Mental Health Journal, 49(5), 587-598. doi:10.1007/s10597-0129559-1

Hawker, S., Payne, S., Kerr, C., Hardey, M., \& Powell, J. (2002). Appraising the evidence: Reviewing disparate data systematically. Qualitative Health Research, 12(9), 1284-1299. doi:10.1177/ 1049732302238251

Henken, T., Huibers, M. J., Churchill, R., Restifo, K. K., \& Roelofs, J. J. (2007). Family therapy for depression. Cochrane Database of Systematic Reviews, (3). Article Number: CD006728. doi:10.1002/ 14651858.CD006728

Higgins, A., Hevey, D., Gibbons, P., O' Connor, C., Boyd, F., McBennett, P., \& Monaghan, M. (2017). Impact of co-facilitated information programmes on outcomes for service users and family members: The EOLAS programmes (paper 2). Irish Journal of Psychological Medicine, 34(1), 29-37. doi:10.1017/ipm.2015.69

Hunt, G. E., Siegfried, N., Morley, K., Sitharthan, T., \& Cleary, M. (2014). Psychosocial interventions for people with both severe mental illness and substance misuse. Schizophrenia Bulletin, 40(1), 18-20. doi:10.1093/schbul/sbt160

Ince, P., Haddock, G., \& Tai, S. (2016). A systematic review of the implementation of recommended psychological interventions for schizophrenia: Rates, barriers, and improvement strategies. Psychology and Psychotherapy: Theory, Research and Practice, 89(3), 324-350. doi:10.1111/papt.12084

Ingvarsdotter, K., Persson, K., Hjärthag, F., \& Östman, M. (2016). How professionals view multifamily psychoeducation: A qualitative study. Psychiatric Quarterly, 87(3), 479-491. doi:10.1007/s11126015-9401-3 
Jewell, T. C., Downing, D., \& McFarlane, W. R. (2009). Partnering with families: Multiple family group psychoeducation for schizophrenia. Journal of Clinical Psychology, 65(8), 868-878. doi:10.1002/ jclp. 20610

Kulhara, P., Chakrabarti, S., Avasthi, A., Sharma, A., \& Sharma, S. (2009). Psychoeducational intervention for caregivers of Indian patients with schizophrenia: A randomised-controlled trial. Acta Psychiatrica Scandinavica, 119(6), 472-483. doi:10.1111/j.1600-0447. 2008.01304.x

Kuller, A. M., Ott, B. D., Goisman, R. M., Wainwright, L. D., \& Rabin, R. J. (2010). Cognitive behavioral therapy and schizophrenia: A survey of clinical practices and views on efficacy in the United States and United Kingdom. Community Mental Health Journal, 46(1), 2-9. doi:10.1007/s10597-009-9223-6

Lucksted, A., McFarlane, W., Downing, D., \& Dixon, L. (2012). Recent developments in family psychoeducation as an evidence-based practice. Journal of Marital and Family Therapy, 38(1), 101-121. doi:10. 1111/j.1752-0606.2011.00256.x

Magliano, L., Fiorillo, A., Malangone, C., De Rosa, C., \& Maj, M. (2006). A memorial tribute: Patient functioning and family burden in a controlled, real-world trial of family psychoeducation for schizophrenia. Psychiatric Services, 57(12), 1784-1791. doi:10.1176/ ps.2006.57.12.1784

Magliano, L., the Family Intervention Working Group, Fiorillo, A., Malangone, C., De Rosa, C., Maj, M., \& Group, F. I. W. (2006). Implementing psychoeducational interventions in Italy for patients with schizophrenia and their families. Psychiatric Services, 57(2), 266-269. doi:10.1176/appi.ps.57.2.266

McCabe, R., Whittington, R., Cramond, L., \& Perkins, E. (2018). Contested understandings of recovery in mental health. Journal of Mental Health, 27(5), 475-481. doi:10.1080/09638237.2018.1466037

McFarlane, W. R., Dixon, L., Lukens, E., \& Lucksted, A. (2003). Family psychoeducation and schizophrenia: A review of the literature. Journal of Marital and Family Therapy, 29(2), 223-245. doi:10.1111/ j.1752-0606.2003.tb01202.x

Michalak, E. E., Yatham, L. N., Wan, D. D., \& Lam, R. W. (2005). Perceived quality of life in patients with bipolar disorder. Does group psychoeducation have an impact?. The Canadian Journal of Psychiatry, 50(2), 95-100. doi:10.1177/070674370505000204

Mirsepassi, Z., Tabatabaee, M., Sharifi, V., \& Mottaghipour, Y. (2018). Patient and family psychoeducation: Service development and implementation in a center in Iran. International Journal of Social Psychiatry, 64(1), 73-79. doi:10.1177/0020764017747910

Murray-Swank, A. B., \& Dixon, L. (2004). Family psychoeducation as an evidence-based practice. CNS Spectrums, 9(12), 905-912. doi:10. 1017/S109285290000972X

National Institute for Health and Care Excellence. (2014). Psychosis and schizophrenia in adults. The NICE guideline on treatment and management-Updated Edition 2014.Retrieved from https://www. nice.org.uk/guidance/cg178/evidence/full-guideline-490503565.

Nilsen, P. (2015). Making sense of implementation theories, models and frameworks. Implementation Science, 10(1), 53. doi:10.1186/ s13012-015-0242-0

O’Hagan, M. (2012). Recovery: Is consensus possible?. World Psychiatry, 11(3), 167-168. doi:10.1002/j.2051-5545.2012.tb00123.x

Petrakis, M., Bloom, H., \& Oxley, J. (2014). Family perceptions of benefits and barriers to first episode psychosis carer group participation. Social Work in Mental Health , 12(2), 99-116. doi:10.1080/ 15332985.2013.836587

Pharoah, F. (2010). Family intervention for schizophrenia. Cochrane Database of Systematic Reviews, (12). Article Number: CD000088. doi:10.1002/14651858.CD000088.pub2

Pickett, S. A., Diehl, S., Steigman, P. J., Prater, J. D., Fox, A., \& Cook, J. A. (2010). Early outcomes and lessons learned from a study of the Building Recovery of Individual Dreams and Goals through Education and Support (BRIDGES) program in Tennessee. Psychiatric Rehabilitation Journal, 34(2), 96-103. doi:10.2975/34.2. 2010.96.103

Pickett-Schenk, S. A., Bennett, C., Cook, J. A., Steigman, P., Lippincott, R., Villagracia, I., \& Grey, D. (2006). Changes in caregiving satisfaction and information needs among relatives of adults with mental illness: Results of a randomized evaluation of a family-led education intervention. American Journal of Orthopsychiatry, 76(4), 545-553. doi:10.1037/0002-9432.76.4.545

Pickett-Schenk, S. A., Lippincott, R. C., Bennett, C., \& Steigman, P. J. (2008). Improving knowledge about mental illness through familyled education: The journey of hope. Psychiatric Services, 59(1), 49-56. doi:10.1176/ps.2008.59.1.49

Poole, R., Smith, D., \& Simpson, S. (2015). Patients' perspectives of the feasibility, acceptability and impact of a group-based psychoeducation programme for bipolar disorder: A qualitative analysis. $B M C$ Psychiatry, 15(1), 184. doi:10.1186/s12888-015-0556-0

Resnick, S. G., \& Rosenheck, R. A. (2008). Integrating peer-provided services: A quasi-experimental study of recovery orientation, confidence, and empowerment. Psychiatric Services, 59(11), 1307-1314. doi:10.1176/ps.2008.59.11.1307

Rummel-Kluge, C., \& Kissling, W. (2008). Psychoeducation in schizophrenia: New developments and approaches in the field. Current Opinion in Psychiatry, 21(2), 168-172. doi:10.1097/YCO. 0b013e3282f4e574

Sherman, M. D., \& Fischer, E. P. (2012). Provider, veteran, and family perspectives on family education in Veterans Affairs communitybased outpatient facilities. Psychological Services, 9(1), 89-100. doi: 10.1037/a0027103

Sherman, M. D., Fischer, E., Bowling, U. B., Dixon, L., Ridener, L., \& Harrison, D. (2009). A new engagement strategy in a VA-based family psychoeducation program. Psychiatric Services, 60(2), 254-257. doi:10.1176/ps.2009.60.2.254

Sin, J., Gillard, S., Spain, D., Cornelius, V., Chen, T., \& Henderson, C. (2017). Effectiveness of psychoeducational interventions for family carers of people with psychosis: A systematic review and meta-analysis. Clinical Psychology Review, 56, 13-24. doi:10.1016/j.cpr.2017. 05.002

Sin, J., Henderson, C., Pinfold, V., \& Norman, I. (2013). The E Sibling Project-exploratory randomised controlled trial of an online multicomponent psychoeducational intervention for siblings of individuals with first episode psychosis. BMC Psychiatry, 13(1), 123. doi:10. 1186/1471-244X-13-123

Slade, M. (2013). 100 Ways to Support Recovery. A guide for mental health professionals. Rethink recovery series (Vol. 1; 2nd ed.). London: Rethink

Slade, M., Adams, N., \& O'Hagan, M. (2012). Recovery: Past progress and future challenges. International Review of Psychiatry, 24(1), 1-4. doi:10.3109/09540261.2011.644847

Slade, M., Amering, M., Farkas, M., Hamilton, B., O'Hagan, M., Panther, G., ... Whitley, R. (2014). Uses and abuses of recovery: Implementing recovery-oriented practices in mental health systems. World Psychiatry, 13(1), 12-20. doi:10.1002/wps.20084

Stuart, B. K., \& Schlosser, D. A. (2009). Multifamily group treatment for schizophrenia. International Journal of Group Psychotherapy, 59(3), 435-440. doi:10.1521/ijgp.2009.59.3.435

Substance Abuse and Mental Health Services Administration (SAMHSA). (2009). Results from the 2008 National Survey on Drug Use and Health: National Findings. Office of Applied Studies. NSDUH Series H-36, HHS Publication No. SMA 09-4434. Rockville, MD: SAMHSA. Rockville, MD. Google Scholar

Taylor, T. L., Killaspy, H., Wright, C., Turton, P., White, S., Kallert, T. W., ... King, M. B. (2009). A systematic review of the international published literature relating to quality of institutional care for people with longer term mental health problems. $B M C$ Psychiatry, 9(1), 55. doi:10.1186/1471-244X-9-55

Tribe, R. H., Sendt, K. V., \& Tracy, D. K. (2019). A systematic review of psychosocial interventions for adult refugees and asylum seekers. Journal of Mental Health, 28(6), 662-676. doi:10.1080/09638237. 2017.1322182

Tsiouri, I., Gena, A., Economou, M. P., Bonotis, K. S., \& Mouzas, O. (2015). Does long-term group psychoeducation of parents of individuals with schizophrenia help the family as a system? A quasiexperimental study. International Journal of Mental Health, 44(4), 316-331. doi:10.1080/00207411.2015.1076294 
Tungpunkom, P., \& Nicol, M. (2008). Life skills programmes for chronic mental illnesses. Cochrane Database of Systematic Reviews, (2). Article Number: CD000381. doi:10.1002/14651858.CD000381. pub3/abstract

Vieta, E. (2005). Improving treatment adherence in bipolar disorder through psychoeducation. Journal of Clinical Psychiatry, 66 (1), 24-29.

Whitley, R., Gingerich, S., Lutz, W. J., \& Mueser, K. T. (2009). Implementing the illness management and recovery program in community mental health settings: Facilitators and barriers. Psychiatric Services, 60(2), 202-209. doi:10.1176/ps.2009.60.2.202

Williams, J., Leamy, M., Bird, V., Harding, C., Larsen, J., Boutillier, C., ... Slade, M. (2012). Measures of the recovery orientation of mental health services: Systematic review. Social Psychiatry and Psychiatric Epidemiology, 47(11), 1827-1835. doi:10.1007/s00127-012-0484-y
World Health Organisation (WHO). (2013). Comprehensive mental health action plan 2013-2020. Geneva: World Health Organisation.

Xia, J., Merinder, L. B., Belgamwar, M. R. (2011). Psychoeducation for schizophrenia. Cochrane Database of Systematic Reviews, (6). Article Number: CD002831. doi:10.1002/14651858.CD002831.pub2

Yesufu-Udechuku, A., Harrison, B., Mayo-Wilson, E., Young, N., Woodhams, P., Shiers, D., ... Kendall, T. (2015). Interventions to improve the experience of caring for people with severe mental illness: Systematic review and meta-analysis. The British Journal of Psychiatry, 206(4), 268-274. doi:10.1192/bjp.bp.114.147561

Zhao, S., Sampson, S., Xia, J., \& Jayaram, M. B. (2015). Psychoeducation (brief) for people with serious mental illness. Cochrane Database of Systematic Reviews, (4). Article Number: CD010823. doi:10.1002/14651858.CD010823.pub2 